\section{MUTATIONS OF p53 IN BARRETT'S ESOPHAGUS AND BARRETT'S CANCER: A PROSPECTIVE STUDY OF NINETY-EIGHT CASES}

We had previously identified p53 mutations in Barrett's esophagus and therefore began a multiinstitutional study to determine their significance as a marker for malignancy. Ninety-eight patients from four institutions were studied. Forty-eight patients ( 37 men and 11 women, mean age 56.2 years) had Barrett's esophagus with metaplasia or dysplasia but no evidence of malignancy at a mean follow-up of 2.2 years. Barrett's esophagus was classified as metaplasia with no evidence of dysplasia in 32 patients, as low-grade dysplasia in 13, and as high-grade dysplasia in three. The other 50 patients (46 men and four women, mean age 60.2 years) had adenocarcinoma arising in Barrett's esophagus. Tissues from normal stomach or esophagus, tumor, and Barrett's esophagus were obtained for deoxyribonucleic acid analysis by endoscopic biopsy from patients with Barrett's esophagus or cancer or during operations on some patients with Barrett's cancer. Exons 5 through 9 of the p53 gene were studied for mutations by single-strand conformational polymorphism analysis after polymerase chain reaction amplification. Mutations detected by single-strand conformational polymorphism analysis were confirmed by deoxyribonucleic acid sequencing. None of the tissue samples from patients with Barrett's esophagus alone and no dysplasia or low-grade dysplasia had any 053 mutations, but one of the three patients with high-grade dysplasia and no evidence of invasive malignancy did have a p53 mutation. Of the 50 patients with Barrett's cancer, however, 23 (46\%) had p53 mutations in Barrett's

Paul M. Schneider, MD (by invitation), ${ }^{\mathrm{a}}$ Alan G. Casson, FRCSC (by invitation), ${ }^{\mathrm{c} *}$ Bernard Levin, MD (by invitation), ${ }^{f}$ Harinder S. Garewal, MD (by invitation), ${ }^{e}$ Arnulf H. Hoelscher, MD (by invitation), ${ }^{a}$ Karen Becker, MD (by invitation), ${ }^{b}$ Hans-Joachim Dittler, MD (by invitation), ${ }^{a}$ Karen R. Cleary, MD (by invitation), ${ }^{\mathrm{g}}$ Michael Troster, MD (by invitation), ${ }^{\mathrm{d}}$ J. Ruediger Siewert, MD (by invitation), ${ }^{a}$ and Jack A. Roth, MD, ${ }^{\text {h }}$ Munich, Germany; London, Ontario, Canada; Tucson, Ariz.; Houston, Tex.
From the Departments of Surgery ${ }^{a}$ and Pathology, ${ }^{b}$ Technical University of Munich Medical Center, Munich, Germany, the Departments of Surgery ${ }^{\mathrm{c}}$ and Pathology, ${ }^{\mathrm{d}}$ University of Western Ontario, London Regional Cancer Center and Victoria Hospital, London, Ontario, Canada, the Departments of Hematology-Oncology and Gastroenterology, Tucson Veterans Administration Medical Center, Tucson, Ariz., ${ }^{e}$ and the Departments of Gastrointestinal Oncology and Digestive Diseases, ${ }^{\mathrm{f}}$ Pathology, ${ }^{\mathrm{g}}$ and Thoracic and Cardiovascular Surgery, The University of Texas M. D. Anderson Cancer Center, Houston, Tex.

Supported by grants from the Deutsche Krebsgesellschaft (German Cancer Society)/Dr. Mildred Sheol Stiftung (M91/91/ H81) to P. M. S. and A. H. H., the National Cancer Institute RO1 CA45187 to J. A. R., by National Cancer Institute Training Grant CA09611 to J. A. R., by gifts to the Division of Surgery from Tenneco and Exxon for the Core Laboratory Facility, and by the M. D. Anderson Cancer Center Support Core Grant (CA16672), by a grant from the Mathers Foun- dation to J. A. R., J. P. Bickell Foundation, Ontario Thoracic Society to A. G. C., Victoria Hospital Research Development Fund and the Department of Surgery Academic Enrichment Fund to A. G. C.

Read at the Seventy-fifth Annual Meeting of The American Association for Thoracic Surgery, Boston, Mass., April 23-26, 1995.

Address for reprints: J. A. Roth, MD, Department of Thoracic and Cardiovascular Surgery, The University of Texas M. D. Anderson Cancer Center, 1515 Holcombe Blvd., Box 109, Houston, TX 77030.

*Current address: The Department of Thoracic Surgery, University of Toronto Mount Sinai Hospital, Toronto, Ontario, Canada.

J Thorac CARdiovasc Surg 1996;111:323-33

Copyright (C) 1996 by Mosby-Year Book, Inc.

$0022-5223 / 96 \$ 5.00+0 \quad \mathbf{1 2 / 6 / 6 9 6 6 7}$ 
epithelium, tumors, or both. Twenty of these patients had p53 mutations in the tumor only $(n=16)$ or in both tumor and Barrett's epithelium $(n=4)$, suggesting that the mutation plays a direct role in carcinogenesis. Mutations in Barrett's epithelium were found in one patient in the group without malignancy and in seven patients with cancer (one with no dysplasia, two with low-grade dysplasia, and five with high-grade dysplasia). In three patients with cancer, mutations occurred only in Barrett's epithelium, suggesting that such mutations may also be a marker for genomic instability. Mutations were predominantly found in exons 5, 7, and 8, and transitions from guanine to adenine were the most frequent changes. Mutations of p53 are clearly involved in the pathogenesis of Barrett's cancer for a subset of patients $(\mathbf{4 6 \%})$, and the fact that we could detect mutations in premalignant Barrett's epithelium supports the hypothesis that p53 mutations may be a useful marker for patients at increased risk for development of invasive cancer. (J THORAC CARDIOvaSC SURG 1996;111: 323-33)

$B_{\text {to }}^{\text {and }}$ arrett's esophagus develops in approximately $10 \%$ to $12 \%$ of patients with chronic gastroesophageal reflux disease. ${ }^{1}$ It is characterized by the replacement of the normal squamous epithelium of the esophagus with a metaplastic columnar epithelium. ${ }^{2}$

The potential for Barrett's epithelium to undergo malignant transformation is well recognized and accepted. ${ }^{3,4}$ In several prospective and retrospective studies, reported incidences of Barrett's cancer ranged from 1 in 56 patient-years to as low as 1 in 441 patient-years, and there was an approximately 30- to 40-fold increased risk for patients with Barrett's esophagus compared with the general population. ${ }^{5}$ In addition, the incidence of adenocarcinomas in Barrett's esophagus and the gastric cardia increased more rapidly than that of any other cancer in the past two decades in the United States. ${ }^{6}$

Several studies support the concept that Barrett's adenocarcinoma does not occur de novo but arises as the result of tumor initiation and progression from benign metaplastic columnar epithelium to varying degrees of dysplasia, carcinoma in situ, and invasive carcinoma., ${ }^{4-9}$ There is substantial evidence that Barrett's cancer is associated with a clonal evolution process as a result of acquired genomic instability through a progressive accumulation of genetic abnormalities, including the occurrence of single or multiple aneuploid cell populations ${ }^{9-12}$ and chromosomal rearrangements. ${ }^{13}$ Allelic losses involving chromosome $17 \mathrm{p}$ are frequently detected in Barrett's carcinoma ${ }^{14}$ and premalignant Barrett's epithelium. ${ }^{15}$

The tumor-suppressor gene p53 is located on chromosome $17 \mathrm{p}$, and wild-type p53 has been implicated in the control of the cell cycle, deoxyribonucleic acid (DNA) repair and synthesis, cell differentiation, genomic stability, and apoptosis. ${ }^{16,17}$ The p53 gene is the most commonly mutated gene in human cancers, ${ }^{18}$ and p53 mutations have also been detected in squamous cell carcinomas of the esophagus. ${ }^{19,20}$ Casson and coworkers ${ }^{21}$ first demonstrated p53 mutations in Barrett's cancer and premalignant Barrett's epithelium; these results were recently reconfirmed. ${ }^{22}$ Additional evidence for the involvement of p53 mutations in the neoplastic progression of Barrett's carcinoma comes from studies of $\mathrm{p} 53$ protein expression by means of multiparameter flow cytometry and immunohistochemistry. ${ }^{23,24}$ The purpose of this study was to determine the significance of p53 mutation as a marker for adenocarcinoma arising in Barrett's epithelium.

\section{Patients and methods}

Study design and demographic data. Between December 1991 and December 1994, patients with Barrett's metaplasia and Barrett's carcinoma were recruited from the following four institutions: Technical University of Munich Medical Center (Munich, Germany), University of Western Ontario, London Regional Cancer Center and Victoria Hospital (London, Ontario, Canada), Tucson Veterans Administration Medical Center (Tucson, Ariz.), and The University of Texas M. D. Anderson Cancer Center, Houston, Texas. The exclusion criteria were previous history of a malignant tumor or radiation therapy or chemotherapy before the tissue specimens to be analyzed were obtained.

A total of 98 patients were evaluated, including 48 patients with Barrett's esophagus only, without evidence of cancer (BE group), and 50 patients with Barrett's 
cancer (BC group). There were 37 men and 11 women in the $\mathrm{BE}$ group; they had a median age of 56.2 years and a median length of Barrett's esophagus of $5.3 \mathrm{~cm}$. The median follow-up was 2.2 years. The degree of dysplasia in metaplastic Barrett's epithelium was evaluated according to the criteria of Riddell, ${ }^{25}$ simplified to include only three categories as suggested by Williamson and associates ${ }^{26}$ : no evidence of dysplasia (NOD), low-grade dysplasia (LGD), and high-grade dysplasia (HGD). Thirty-two patients had NOD, 13 had LGD, and three had HGD.

Barrett's cancer was defined as adenocarcinoma originating above the gastroesophageal junction in association with characteristic columnar mucosa. At least $75 \%$ of the tumor had to occupy the tubular esophagus. ${ }^{27}$ The BC group included 46 men and four women, with a median age of 60.3 years. Forty-eight of the 50 patients underwent surgical resection, and two of the 50 patients received primary radiochemotherapy for palliation. Tumor staging was performed according to the International Union Against Cancer (IUCC) TNM classification (4th ed., 2nd revision, 1992): 16 patients had stage I tumors, 15 had stage II tumors, 16 had stage III tumors, and three had stage IV tumors. The primary tumors were graded histopathologically as well-differentiated (G1, nine patients), moderately differentiated (G2, 18 patients), poorly differentiated (G3, 19 patients), and undifferentiated (G4, four patients).

Tissue acquisition. Tissue for DNA analysis was obtained from patients with Barrett's esophagus (BE group) by endoscopic biopsy. At least two separate areas were sampled routinely, one within 1 to $2 \mathrm{~cm}$ above the cardia and one approximately 1 to $2 \mathrm{~cm}$ distal to the border between squamous epithelium and Barrett's epithelium. In patients with Barrett's cancer (BC group), tissue was obtained by endoscopic biopsy or at operation. Tissues from the following locations were analyzed: tumor, peritumoral Barrett's epithelium, and Barrett's epithelium as far from the tumor as possible. If there was only a small area of tumor-free Barrett's epithelium (as in some pT3 and pT4 tumors), only peritumoral Barrett's epithelium was analyzed. For both groups, normal tissues were taken from the gastric fundus and squamous epithelium of the esophagus. All tissue specimens were immediately frozen in liquid nitrogen or fixed in formaldehyde. Conventional histologic analysis of all tissue specimens analyzed for p53 mutations was performed by gastrointestinal pathologists (K. B. for the German subjects and K. R. C. and M. T. for the North American subjects). This study was approved by the internal review boards of all involved institutions.

DNA amplification, polymerase chain reaction (PCR) single-strand conformation polymorphism (SSCP) analysis, and DNA sequencing. DNA was isolated with a DNA extraction kit (Stratagene Inc., La Jolla, Calif.). Exons 5 through 9 of the p53 gene were analyzed because more than $90 \%$ of mutations in the p53 gene occur in this evolutionarily conserved part of the gene. ${ }^{28}$ For PCR amplification, oligonucleotide primer pairs for exons 5 through 9 derived from p53 sequences deposited in GenBank by Peter Clumakov (accession no. X54156) were chosen as reported. ${ }^{29} \mathrm{~A} 0.1 \mu \mathrm{g}$ portion of DNA was added to a $25 \mu \mathrm{l}$ reaction mixture containing $1 \mu \mathrm{mol} / \mathrm{L}$ of each primer (MWG Biotech, Ebersberg, Germany), or synthe- sized with a DNA synthesizer (model 392; Applied Biosystems, Foster City, Calif.), $1.5 \mathrm{mmol} / \mathrm{L}$ magnesium chloride, $10 \mathrm{mmol} / \mathrm{L}$ tris-hydroxymethyl-amino methane hydrochloride $(\mathrm{pH} 8.3), 50 \mathrm{mmol} / \mathrm{L}$ potassium chloride, and $0.001 \%$ gelatin (all reagents from Sigma Chemical Co., Munich, Germany, or St. Louis, Mo.), $200 \mu \mathrm{mol} / \mathrm{L}$ each deoxyadenosine triphosphate, deoxycytidine triphosphate (dCTP), deoxyguanosine triphosphate, dCTP (Pharmacia, Stockholm, Sweden) for nonradioactive SSCP or a mixture of $100 \mu \mathrm{mol} / \mathrm{L}$ dCTP and $\alpha-{ }^{32} \mathrm{P}-\mathrm{dCTP}$ (Amersham Corp., Arlington Heights, Ill.) for radioactive SSCP, and 0.625 U Taq polymerase (Pharmacia). The samples were amplified with a Perkin Elmer Cetus Thermocycler 480 (Perkin-Elmer Corp., Norwalk, Conn.) under the following conditions: an initial denaturation step at $94^{\circ} \mathrm{C}$ for 5 minutes and 35 cycles of denaturation at $94^{\circ} \mathrm{C}$ for 1 minute, annealing at $58^{\circ} \mathrm{C}$ for 1 minute, and elongation at $72^{\circ} \mathrm{C}$ for 1 minute. The PCR products were checked on a $3 \%$ GeneAmp agarose gel (Perkin-Elmer). Two types of SSCP analysis were performed: a nonradioactive form that used the Pharmacia PCR-Fragment Analysis Kit, with $15 \%$ polyacrylamide gel electrophoresis horizontal at $15^{\circ} \mathrm{C}$ and silver staining according to the manufacturer's recommendations, and a radioactive form with vertical $12 \%$ polyacrylamide gel electrophoresis at $4^{\circ} \mathrm{C}$, with $0.5 \mathrm{x}$ Tris-borate-ethylenediaminetetraacetic acid running buffer as reported previously. ${ }^{30}$ SSCP analysis was performed at least twice by each procedure, and DNA sequencing was performed on samples that showed an electrophoretic mobility shift. Three samples that had unequivocal mobility shifts could not be sequenced because not enough DNA was available. Direct sequencing of both strands of the PCR products was performed after amplification with paired biotinylated and nonbiotinylated primers (MWG Biotech) and strand separation with strepavidin-coated magnetic beads (Dynal Inc., Hamburg, Germany) by solid-phase single-strand sequencing with the Sequenase version 2.0 Sequencing Kit (United States Biochemical, Cleveland, Ohio) according to the manufacturer's recommendations. For samples with exon 5 mobility shifts and samples found to have mutation by SSCP but not by direct DNA sequencing, subcloning and double-strand DNA sequencing were performed with the TA-Cloning Kit (InVitrogen, San Diego, Calif.).

\section{Results}

Prevalence of p53 mutations in $\mathrm{BE}$ and $\mathrm{BC}$ groups. SSCP analysis and DNA sequencing revealed p 53 mutations in one of 48 patients in the $B E$ group and 23 of 50 patients in the $\mathrm{BC}$ group. Representative examples of SSCP analyses and DNA sequencing are shown in Figs. 1 and 2.

In a patient in the BE group, a p53 mutation in exon 5 was present in an area of HGD, but two additional areas with LGD, had no mutations. In the $\mathrm{BC}$ group, 16 patients had p53 mutations in their tumors but not in peritumoral Barrett's epithelium or distant Barrett's epithelium. Four patients had 

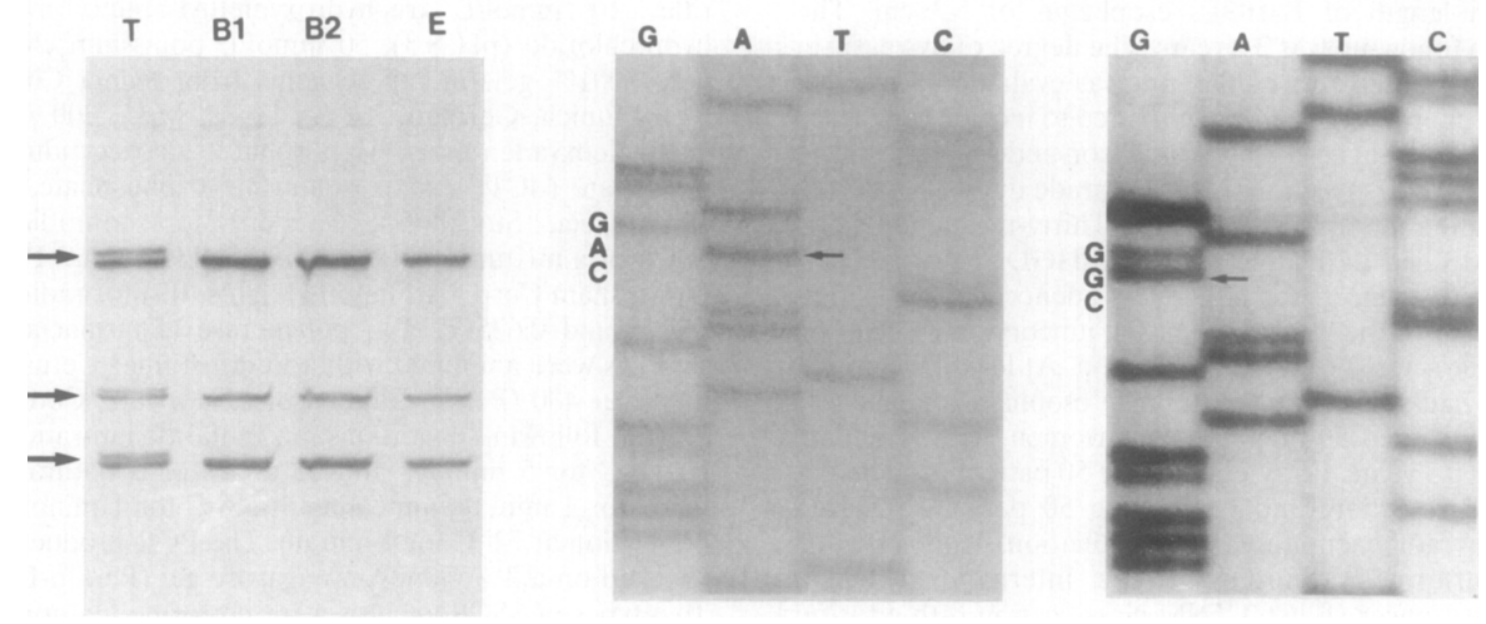

Fig. 1. Left panel, PCR SSCP analysis of exon 8 in a patient with Barrett's cancer (patient 28). Specimens were analyzed from the tumor (T1), two separate foci of Barrett's epithelium with LGD (B1) and NOD $(B 2)$, and histologically normal esophageal squamous epithelium (E). An electrophoretic mobility shift (aberrant bands) is clearly detected in T1 (arrows). Right panel, DNA sequencing of tumor $(T)$ and epithelium $(E)$ showed a guanine to adenine transition mutation (arrow) in codon (CGG $\rightarrow$ CAG) that resulted in an amino acid change (glycine $\rightarrow$ arginine).
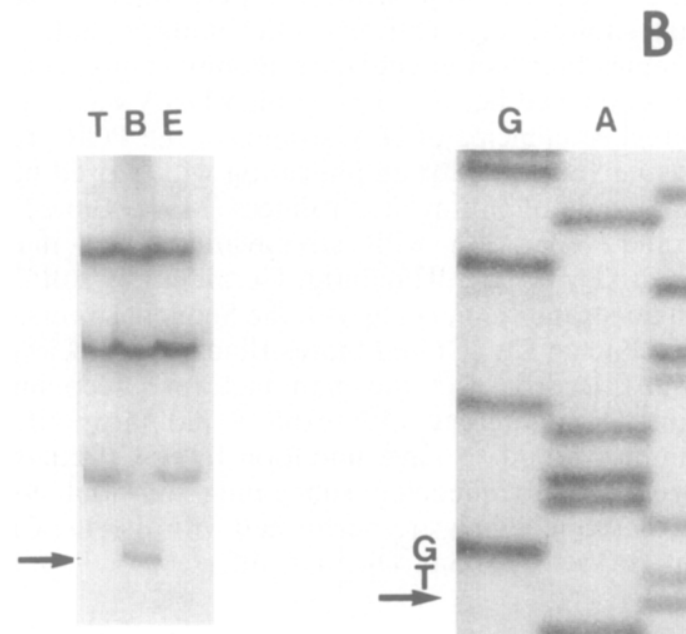

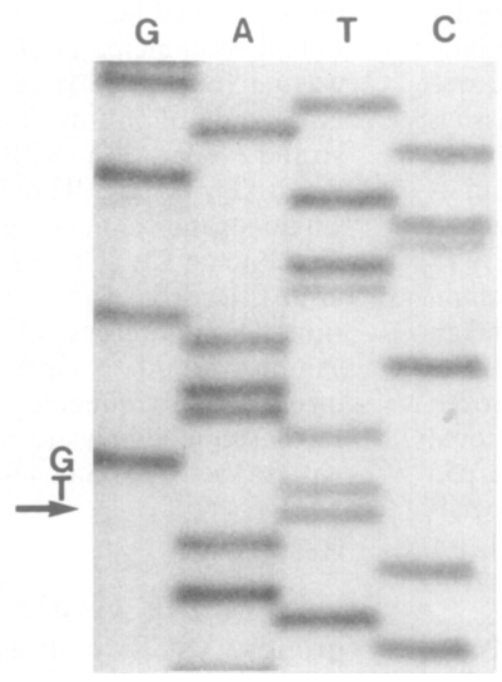

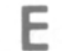

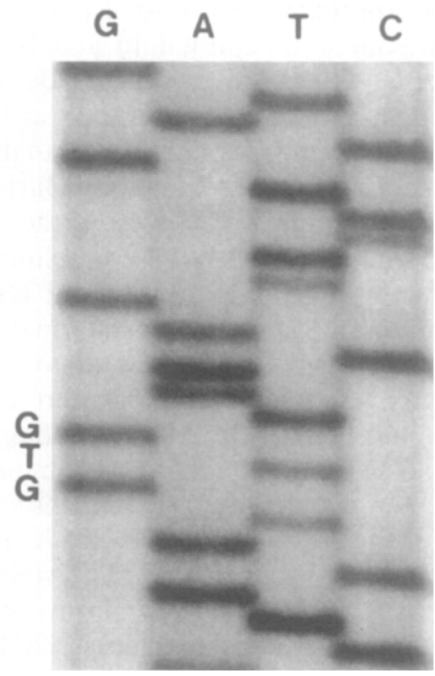

Fig. 2. Left panel, PCR SSCP analysis of exon 7 in a patient with Barrett's cancer (patient 2). Specimens were analyzed from the tumor $(T)$, Barrett's epithelium with no evidence of dysplasia $(B)$, and histologically normal squamous esophageal epithelium (E). An electrophoretic mobility shift was detected in B (arrow). Right panel, DNA sequencing of B and $\mathrm{E}$ revealed a one base pair guanine deletion (arrow) in codon 237 (GTG $\rightarrow$ TG), which resulted in a frameshift.

mutations both in their tumors and in Barrett's epithelium. Two of the four had identical mutations in their tumors and peritumoral Barrett's epithelium with HGD. The mutations were located in exon 8 in both patients and were a missense mutation in codon 278 (CCT $\rightarrow$ CTT; cytosine to thymine transition) and a frameshift mutation in codons 316-317 (CCCCAG $\rightarrow$ CCCCCAG, cytosine inser- 
Volume 111, Number 2

Table I. Characteristics of patients with p53 mutations in Barrett's cancer (BC group)

\begin{tabular}{|c|c|c|c|c|c|c|c|c|}
\hline $\begin{array}{l}\text { Patient } \\
\text { no. }\end{array}$ & Age & Sex & $\begin{array}{l}U I C C \\
\text { stage }\end{array}$ & Grade & $\begin{array}{c}\text { Histology of } \\
\text { Barrett's } \\
\text { epithelium }\end{array}$ & $\begin{array}{l}\text { Mutation } \\
\text { in tumor }\end{array}$ & $\begin{array}{c}\text { Mutation in } \\
\text { Barrett's } \\
\text { epithelium }\end{array}$ & Group \\
\hline 2 & 65 & M & III & G3 & LGD & Exon $7 / \mathrm{DEL}$ & $\mathrm{NEG}$ & I \\
\hline 4 & 63 & M & III & G3 & LGD & Exon 5/TS & NEG & I \\
\hline 5 & 56 & $\mathbf{M}$ & III & G2 & HGD & Exon 7/TS & NEG & I \\
\hline 7 & 57 & M & III & G3 & LGD & Exon $7 /$ TS & NEG & I \\
\hline 10 & 56 & $\mathrm{M}$ & II & G2 & NOD & Exon $5 / \mathrm{TS}$ & NEG & I \\
\hline 12 & 62 & $\mathrm{M}$ & II & G4 & NOD & NEG & Exon 7/DEL & IV \\
\hline 14 & 83 & $\mathrm{M}$ & II & G3 & NOD & Exon 5/TS & NEG & I \\
\hline 18 & 60 & $\mathrm{M}$ & III & G3 & HGD & Exon 5/DEL & NEG & I \\
\hline 20 & 70 & $\mathrm{M}$ & I & $\mathrm{G} 2$ & LGD & $\mathrm{NEG}$ & Exon 7/TS & IV \\
\hline 22 & 49 & M & I & G1 & LGD & Exon 5/DEL & $\mathrm{NEG}$ & I \\
\hline 27 & 61 & M & I & $\mathrm{G} 2$ & $\operatorname{LGD}(+)$ & Exon 5/TS & NEG & $\mathrm{I}$ \\
\hline 28 & 59 & $\mathrm{M}$ & I & $\mathrm{G} 1$ & HGD & Exon $8 / \mathrm{TS}$ & Exon 8/TS & II \\
\hline 30 & 72 & $\mathrm{~F}$ & III & G3 & $\operatorname{LGD}(+)$ & Intron $4 /$ exon $5 / \mathrm{TS}$ & Exon 9/ND & III \\
\hline 31 & 65 & $\mathrm{M}$ & IV & G3 & HGD & Exon $8 / \mathrm{TV}$ & Exon $7 / T S$ & III \\
\hline 32 & 58 & M & II & G3 & HGD & NEG & Exon 5/DEL & IV \\
\hline 34 & 54 & $\mathrm{M}$ & III & $\mathrm{G} 2$ & HGD & Exon $8 / \mathrm{TS}$ & NEG & I \\
\hline 36 & 58 & M & I & $\mathrm{G} 2$ & LGD & Exon $6 /$ TS & NEG & I \\
\hline 38 & 71 & $\mathrm{M}$ & I & $\mathrm{G} 1$ & NOD & Exon 6/ND & NEG & I \\
\hline 39 & 58 & M & I & $\mathrm{G} 1$ & NOD & Exon 7/TS & NEG & I \\
\hline 41 & 52 & M & III & G3 & NOD & Exon $8 / \mathrm{TS}$ & NEG & I \\
\hline 44 & 78 & $\mathrm{M}$ & III & G3 & LGD & Exon 6/DEL & NEG & II \\
\hline 46 & 68 & M & III & G1 & LGD & Exon 8/INS & Exon 8/INS & II \\
\hline 49 & 73 & $\mathrm{M}$ & I & G3 & HGD & Exon $7 / N D$ & NEG & I \\
\hline
\end{tabular}

Group classification based on the presence or absence of p 53 mutations in tumor or Barrett's epithelium: $I$, Mutation in tumor; $I I$, identical mutation in tumor and Barrett's epithelium; $I I$, discordant mutation in tumor and Barrett's epithelium; $I$, mutation only in Barrett's epithelium. $D E L$, deletion; $N E G$, no mutations; $T S$, transition; $T V$, transversion; $N D$, not determined; $I N S$, insertion.

tion). The other two patients had different mutations in the tumor and Barrett's epithelium. One patient had a missense mutation in codon 275 of exon 8 (TGT $\rightarrow$ TTT; guanine to thymine transversion) in the tumor and a missense mutation in codon 248 of exon 7 (CGG $\rightarrow$ TGG; cytosine to thymine transition) in peritumoral Barrett's epithelium with HGD. The other patient had a splice-site mutation (junction of intron 4 and exon 5) and a mutation in exon 9 in Barrett's epithelium distant from the tumor with LGD.

Three patients had mutations in areas of Barrett's epithelium but the corresponding tumors did not show p53 mutation. In two patients, the Barrett's epithelium samples with the p53 mutations were from peritumoral areas with NOD (exon 7 mutation) and HGD (exon 5 mutation). In one patient, Barrett's epithelium with LGD distant from the tumor had an exon 7 mutation.

Relationship of $\mathrm{p53}$ mutations to tumor stage, grading, and dysplasia in Barrett's epithelium. Mutations of p53 occurred in tumors of all tumor stages (Table I). The presence of p53 mutations in seven IUCC stage I cancers indicates that the mutational event occurred relatively early in tumor development. In two patients, peritumoral Barrett's epithelium with HGD and the tumor had the same mutation; one tumor was classified as stage I, demonstrating that the mutation preceded tumor development. This is further substantiated by the presence of a p53 mutation in a BE-group patient with HGD without evidence of invasive carcinoma. Mutations were observed in well, moderately, and poorly differentiated tumors but not in undifferentiated tumors; however, there were few G4 tumors (four) in our series (50).

One patient with NOD, two with LGD, and five with HGD had p53 mutations. Although mutations were observed more frequently in areas of the esophagus with HGD, they were also observed before the development of HGD.

Location and type of p53 mutations. A total of 27 specimens from the $\mathrm{BE}$ and $\mathrm{BC}$ groups had p53 mutations. The location and types of mutations that occurred are summarized in Table II. Mutations were most frequently present in exon $5(35.7 \%)$, followed by exons $7(28.6 \%)$ and $8(25 \%)$. Mutations in exons 6 and 9 appeared to occur rarely. Twenty-four of 27 unequivocal mutations, as determined by SSCP could be sequenced and character- 
Table II. Locations and types of p53 mutations

\begin{tabular}{lccccccr}
\hline \multicolumn{1}{c}{ Mutation } & Exon & Exon & Exon & Exan & Exon & & \\
\hline Transition & 5 & 6 & 7 & 8 & 9 & \multicolumn{1}{c}{$n$} & $\%$ \\
Transversion & 0 & 1 & 5 & 4 & 0 & 14 & 50.0 \\
Deletion & 4 & 0 & 0 & 1 & 0 & 1 & 3.6 \\
Insertion & 0 & 0 & 0 & 2 & 0 & 2 & 7.1 \\
Splice site & 1 & 1 & 0 & 0 & 0 & 2 & 7.1 \\
Not analyzed & 1 & 0 & 1 & 0 & 1 & 3 & 10.7 \\
$n$ & 10 & 2 & 8 & 7 & 1 & 28 & 100 \\
$\%$ & 35.7 & 7.1 & 28.6 & 25 & 3.6 & 100 & \\
\hline
\end{tabular}

ized. The most frequent type of mutation in the p53 gene was a transition (14 of 24), which led in all cases to a change in the amino-acid sequence. Amiong these transition mutations, guanine to adenine transitions were most common $(n=8)$, followed by cytosine to thymine $(n=4)$ and adenine to guanine $(n=2)$ transitions. Four transitions occurred at cytosine-guanine dinucleotides. Deletions were the next most common mutations (six of 24); four were 1 base pair, one was 2 base pairs, and one was 11 base pairs; all caused frameshifts. Insertions and transversions were rare, observed in only one patient each.

\section{Discussion}

Casson and coworkers ${ }^{21}$ first reported p53 mutations in Barrett's epithelium and carcinomas; more recently, Neshat and associates ${ }^{22}$ found p53 mutations in seven of 12 patients with Barrett's cancer. The results of our analysis of a larger sample were consistent with the results of these studies, which indicated that p53 mutations occurred in approximately $46 \%$ to $56 \%$ of patients with Barrett's cancer. These patients could be classified into five groups on the basis of the presence and absence of p53 mutations: group I (32\%), p53 mutation only in the tumor; group II (4\%), concordant p53 mutations in the tumor and Barrett's epithelium; group III (4\%), discordant p53 mutations in the tumor and Barrett's epithelium; group IV (6\%), p53 mutation only in Barrett's epithelium; and group V (54\%), no p53 mutation in either the tumor or Barrett's epithelium.

The existence of groups I and II is consistent with a process of clonal evolution, a mechanism proposed by Nowell. ${ }^{31}$ Using flow-cytometry in a prospective study of patients with Barrett's esophagus, Reid and colleagues $^{9}$ reported that progression to adenocarcinoma is associated with a clonal evolution process. This process included the development of single or multiple aneuploid cell populations ${ }^{11}$ and allelic losses on chromosomes $17 \mathrm{p}$ and $5 \mathrm{q}^{32}$ involving the $\mathrm{p} 53, \mathrm{APC}, \mathrm{MCC}$, and $\mathrm{Rb}$ gene loci. ${ }^{32}$ The existence of group II provides evidence that p53 mutation probably occurs before the development of invasive carcinoma in premalignant Barrett's epithelium, as has been reported for other aerodigestive tract cancers. $^{16,18,33,34}$

Discordant mutations in tumor and premalignant epithelium (group III) have already been reported in squamous cell carcinomas of the esophagus, ${ }^{34}$ suggesting that multifocal neoplasms can arise in both esophageal squamous cell carcinomas and Barrett's associated adenocarcinomas. The same conclusion could apply to group IV, patients with p53 mutation in Barrett's epithelium but not the tumor. Multiple areas of different degrees of dysplasia can exist in the same patient with Barrett's esophagus or Barrett's cancer and can include the occurrence of multiple aneuploid cell populations. ${ }^{9,11,22}$ Progression to cancer in patients with Barrett's esophagus has been shown to be associated with increased genomic instability. ${ }^{10}$ It is therefore likely that a clone without p53 mutation but with a selective growth advantage formed a malignant tumor and that an area of Barrett's epithelium with a p53 mutation was at an earlier stage of tumorigenesis. This histologic pattern could also be explained by the field cancerization theory, ${ }^{35}$ which would imply that the metaplastic Barrett's epithelium of these patients would be at increased risk for cancer development.

Demonstration of p53 mutations in one of three patients in the BE group with HGD, in premalignant Barrett's epithelium in patients with Barrett's carcinoma, and in early Barrett's carcinomas (UICC stage I) is consistent with previous reports ${ }^{21,22}$ that p53 mutations must occur at an early stage of tumor development and may precede the formation of microinvasive tumors. Mutations of p53, however, were not detected in 47 patients of the $\mathrm{BE}$ group with NOD or LGD. This does not contradict our hypothesis, because the median follow-up period was 2.2 years and the incidence of Barrett's cancer is approximately one in 56 to one in 441 patient-years. ${ }^{5}$

Overexpression of p53 protein was first shown in a subset of Barrett's carcinomas. ${ }^{14}$ Ramel and coworkers $^{23}$ detected $\mathrm{p} 53$ protein overexpression in Barrett's metaplasia in one of 21 patients $(5 \%)$ with NOD, two of 13 with LGD (15\%), five of 11 with HGD (45\%), and eight of 15 with Barrett's carcinoma $(53 \%)$. Younes and colleagues ${ }^{24}$ found positive immunostaining for p53 in no cases with NOD, 
Volume 111, Number 2

$9 \%$ of cases with LGD, 55\% with HGD, and $87 \%$ with adenocarcinoma. Rice and associates ${ }^{36}$ reported that no p53 immunoreactivity was seen in Barrett's metaplasia with NOD or LGD and that positive immunostaining occurred in $69 \%$ of specimens with HGD, $67 \%$ with intramucosal cancer, and $40 \%$ with submucosal cancer. A study by Jones and colleagues ${ }^{37}$ showed significant p53 immunoreactivity in Barrett's esophagus specimens with NOD $(10 \%)$, LGD (60\%), and HGD (100\%); however, adenocarcinomas in Barrett's esophagus showed significant p53 expression in only $70 \%$ of specimens. The disparate results of these studies are difficult to interpret and could reflect variations in observer interpretation and the use of different antibodies and staining procedures. In addition, p53 protein is expressed at very low levels in most cell types, and wild-type p53 expression might be increased by mechanisms other than gene mutations. ${ }^{17}$ The correlation between increased immunoreactivity and the presence of mutations is imperfect. For example, frameshift or chain-terminating (nonsense) mutations and deletions may not be detected, because the resultant protein is absent, truncated, or unstable. ${ }^{16}$ The wild-type p53 protein may spontaneously change its conformation in cancer cells and assume a mutant conformation. ${ }^{38,39}$ This conformational change would be detected by monoclonal antibodies that recognize the mutant conformation. The use of certain antibodies could overestimate the incidence of p53 mutations on the basis of the level of p53 expression.

Our results indicate that it is likely that the vast majority of the positive immunostaining seen in Barrett's metaplasia with NOD or LGD does not reflect the presence of p53 mutation. We did not detect p53 mutations in any of the 32 patients with NOD or the 13 patients with LGD in the BE group.

Allelic deletions of chromosome $17 p$ have been reported in Barrett's carcinomas and Barrett's dysplasia. ${ }^{14,15}$ Although allelic deletions are frequently associated with p53 mutations in the remaining allele, such mutations (which are required to inactivate the tumor-suppressor-gene) need to be demonstrated to conclude that p53 tumor-suppressor function is absent. ${ }^{17}$ Empirically, loss of $17 \mathrm{p}$ includes loss of a normal p53 gene; however, another cancerrelated gene on $17 \mathrm{p}$ could also be lost, so the effect of the loss of p53 function is therefore much more precisely assessed by direct analysis of the p53 gene. $^{18}$

In our study, p53 mutations in premalignant Bar- rett's epithelium and Barrett's cancer were more frequent in exons 5, 7, and 8 than in exons 6 and 9. Mutational hot spots for $\mathrm{p} 53$ have been reported for hepatocellular carcinoma in codon $249^{40}$ and for colon carcinomas in codons 175,248 , and $273 .{ }^{18} \mathrm{Six}$ of 24 p 53 mutations ( $25 \%$ ) that could be analyzed by DNA sequencing were in codons 248 and 273. In addition, most of the mutations were transitions of a guanine-cytosine to an adenosine-thymine base pair, which also frequently occur in colon ${ }^{18}$ and gastric carcinomas. ${ }^{41}$ Squamous cell carcinomas of the esophagus and lung cancers show a predominance of transversion mutations in p53, ${ }^{19,20}$ however, and both cancers are tobacco-related diseases. ${ }^{18}$ This observation suggests that the two types of esophageal cancer arise by different mechanisms; transversions are associated with exposure to exogenous carcinogens (e.g., tobacco smoke) and transitions may involve spontaneous deamination of 5methylcytosine at cytosine-guanine dinucleotides. ${ }^{42}$ In addition, oxygen radicals enhance the rate of deamination of deoxynucleotides, and chronic inflammation and nitric oxide produced by nitric oxide synthase may contribute to the high frequency of transition mutations such as of a guanine-cytosine to an adenosine-thymine base pair. ${ }^{43}$ It is important to determine whether inducible nitric oxide synthase is constitutively overexpressed in Barrett's metaplasia as it is in ulcerative colitis, ${ }^{44,45}$ a disease with a high risk for the development of colorectal cancer. ${ }^{46}$

In summary, our study shows that p53 gene mutations were involved in the development of Barrett's cancer in some patients. Although it seems likely that p53 mutations occur in patients with Barrett's esophagus before the development of invasive cancer in Barrett's epithelium with LGD or even NOD, prospective studies of well-defined cohorts of patients with Barrett's esophagus with extended follow-up are needed to confirm this hypothesis. One of us (P. M. S.) is proceeding with this study. In the absence of such data, it is reasonable to consider p53 as a marker gene for the development of adenocarcinoma in Barrett's esophagus. We believe that the presence of a documented p53 mutation in Barrett's metaplasia or dysplasia indicates a high risk for the development or presence of adenocarcinoma. The patient should therefore undergo esophagoscopy at 3-month intervals, with appropriate biopsy samples obtained. If a p53 mutation is documented in HGD, esophagectomy should be considered because of the high probability of invasive carcinoma. 


\section{REFERENCES}

1. Sjogren RW, Johnson LF. Barrett's esophagus: a review. Am J Med 1983;74:313-20.

2. Spechler SJ, Goyal RK. Barrett's esophagus. N Engl J Med 1987;315:362-71.

3. Reid B. Barrett's esophagus and esophageal adenocarcinoma. Gastroenterol Clin North Am 1991;20: 817-34.

4. Hamilton SR, Smith RR. The relationship between columnar epithelial dysplasia and invasive adenocarcinoma arising in Barrett's esophagus. Am $\mathbf{J}$ Clin Pathol 1987;87:301-12.

5. Altorki NK, Skinner DB. Adenocarcinoma in Barrett's esophagus. Semin Surg Oncol 1990;6:274-8.

6. Blot WJ, Devesa SS, Kneller RW, Fraumeni JF Jr. Rising incidence of adenocarcinoma of the esophagus and gastric cardia. JAMA 1991;265:1287-9.

7. Haggitt RC, Tryzelaar J, Ellis FH, Colcher H. Adenocarcinoma complicating columnar epitheliumlined (Barrett's) esophagus. Am J Clin Pathol 1978; $70: 1-5$.

8. Hameeteman W, Tytgat GN, Houthoff HJ, Van Den Tweel JG. Barrett's esophagus: development of dysplasia and adenocarcinoma. Gastroenterology 1989; 96:1249-56.

9. Reid BJ, Blount PL, Rubin CE, Levine DS, Haggitt RC, Rabinovitch PS. Flow-cytometric and histological progression to malignancy in Barrett's esophagus: prospective endoscopic surveillance of a cohort. Gastroenterology 1992;102:1212-9.

10. Rabinovitch PS, Reid BJ, Haggitt RC, Norwood TH, Rubin CE. Progression to cancer in Barrett's esophagus is associated with genomic instability. Lab Invest 1988;60:1:65-71.

11. Raskind WH, Norwood T, Levine DS, Haggitt RC, Rabinovitch PS, Reid BJ. Persistent cloncal areas and expansion in Barrett's esophagus. Cancer Res 1992; 52:2946-50.

12. Fennerty MB, Sampliner RE, Way D, Riddell R, Steinbrom K, Garewal HS. Discordance between flow cytometric abnormalities and dysplasia in Barrett's esophagus. Gastroenterology 1989;97:815-20.

13. Garewal HS, Sampliner R, Liu Y, Trent JM. Chromosomal rearrangement in Barrett's esophagus: a premalignant lesion of esophageal adenocarcinoma. Cancer Genet Cytogenet 1989;42:281-6.

14. Blount PL, Ramel S, Raskind WH, et al. 17 allelic deletions and p53 protein overexpression in Barrett's adenocarcinoma. Cancer Res 1991;51:5482-6.

15. Blount PL, Meltzer SJ, Yin J, Huang Y, Krasna MJ, Reid BJ. Clonal ordering of $17 \mathrm{p}$ and $5 \mathrm{q}$ allelic losses in barrett dysplasia and adenocarcinoma. Proc Natl Acad Sci U S A 1993;90:3221-5.

16. Harris CC, Hollstein M. Clinical implications of the p53 tumor-suppressor gene. N Engl J Med 1993;329: 1318-27.
17. Vogelstein B, Kinzler KW. p53 functions and dysfunction. Cell 1992;70:523-6.

18. Hollstein M, Sidransky D, Vogelstein B, Harris CC. p53 mutations in human cancers. Science 1991;253: 49-53.

19. Hollstein MC, Metcalf RA, Welsh JA, Montesano R, Harris CC. Frequent mutation of the p53 gene in human esophageal cancer. Proc Natl Acad Sci U S A 1990;87:9958-61.

20. Wagata T, Shibagaki I, Imamura M, et al. Loss of 17 $p$, mutation of the p53 gene, and overexpression of p53 protein in esophageal squamous cell carcinomas. Cancer Res 1993;53:846-50.

21. Casson AG, Mukhopadhyay T, Cleary KR, Ro JY, Levin B, Roth JA. p53 gene mutations in Barrett's epithelium and esophageal cancer. Cancer Res 1991; 51:4495-9.

22. Neshat K, Sanchez CA, Galipeau PC, et al. p53 mutations in Barrett's adenocarcinoma and highgrade dysplasia. Gastroenterology 1994;106:1589-95.

23. Ramel S, Reid BJ, Sanchez CA, et al. Evaluation of p53 protein expression in Barrett's esophagus by two-parameter flow cytometry. Gastroenterology 1992;102:1220-8.

24. Younes M, Lebovitz RM, Lechago LV, Lechago J. p53 protein accumulation in Barrett's metaplasia, dysplasia, and carcinoma: a follow-up study. Gastroenterology 1993;105:1637-42.

25. Riddell RH. Dysplasia and regression in Barrett's epithelium. In: Spechler SJ, Goyal RK, eds. Barrett's esophagus. New York: Elsevier, 1985:224-9.

26. Williamson WA, Ellis FH, Gibb SP. Barrett's esophagus: prevalence and incidence of adenocarcinoma. Arch Intern Med 1991;151:2212-6.

27. Streitz JM, Ellis FH, Gibb SP, Balogh K, Watkins E. Adenocarcinoma in Barrett's esophagus: a clinicopathologic study of 65 cases. Ann Surg 1991;213: 122-5.

28. Nigro JM, Baker SJ, Preisinger AC, et al. Mutations in the $p 53$ gene occur in diverse human tumor types. Nature 1989;342:705-8.

29. Imamura J, Bartram CB, Berthold F, Harms D, Nakamura H, Koeffler HP. Mutation of the p53 gene in neuroblastoma and its relationship with N-myc amplification. Cancer Res 1993;53:4053-8.

30. Spinardi L, Mazars R, Theillet C. Protocols for an improved detection of point mutations by SSCP. Nucleic Acids Res 1991;19:4009.

31. Nowell PC. The clonal evolution of tumor cell populations. Science 1976;194:23-8.

32. Huang Y, Boynton RF, Blount PL, et al. Loss of heterozygosity involves multiple tumor suppressor genes in human esophageal cancers. Cancer Res 1992;52:6525-30.

33. Chung KY, Mukhopadhyay T, Kim J, et al. Discordant p53 gene mutations in primary head and neck 
cancers and corresponding second primary cancers of the upper aerodigestive tract. Cancer Res 1993;53: 1676-83.

34. Bennett WP, Hollstein MC, Metcalf RA, et al. p53 mutation and protein accumulation during multistage human esophageal carcinogenesis. Cancer Res 1992; 52:6092-7.

35. Slaughter DP, Southwick HW, Smejkal W. "Field cancerization" in oral stratified squamous epithelium. Cancer 1953;6:963-8.

36. Rice TW, Goldblum JR, Falk GW, Tubbs RR, Kirby $\mathrm{TJ}$, Casey G. p53 immunoreactivity in Barrett's metaplasia, dysplasia, and carcinoma. J THORAC CARDIoVASC SURG 1994;108:1132-7.

37. Jones DR, Davidson AG, Summers CL, Murray GF, Quinlan DC. Potential application of p53 as an intermediate biomarker in Barrett's esophagus. Ann Thorac Surg 1994;57:598-603.

38. Milner J, Watson JV. Addition of fresh medium induces cell cycle and conformation changes in p53, a tumour suppressor protein. Oncogene 1990;5:168390.

39. Spandau DF. Distinct conformations of p53 are observed at different stages of keratinocyte differentiation. Oncogene 1994;9:1861-8.

40. Hsu IC, Metcalf RA, Sun T, Welsh JA, Wang NJ, Harris CC. Mutational hotspot in the p53 gene in human hepatocellular carcinomas. Nature 1991;350: 427-8.

41. Renault B, Van den Broek M, Fodde R, et al. Base traditions are the most frequent genetic change at p53 in gastric cancer. Cancer Res 1993;53:2614-7.

42. Rideout WM 3rd, Coetzee GA, Olumi AF, Jones PA. 5 -Methylcytosine as an endogenous mutagen in the LDL receptor and p53 genes. Science 1990;249:128890.

43. Routledge MN, Wink DA, Keefer IK, Dipple A. Mutations induced by saturated aqueous nitric oxide in the pSP189 supF gene in human Ad293 and E. coli MBM7070 cells. Carcinogenesis 1993;14:1251-4.

44. Boughton-Smith NK, Evans SM, Hawkey CJ, et al. Nitric oxide synthase activity in ulcerative colitis and Crohn's disease. Lancet 1993;342:338-40.

45. Middleton SJ, Shorthouse M, Hunter JO. Increase nitric oxide synthesis in ulcerative colitis. Lancet 1993;341:465-6.

46. Ekbom A. Ulcerative colitis and colorectal cancer: a population based study. N Engl J Med 1990;323:122833.

\section{Discussion}

Dr. Thomas W. Rice (Cleveland, Ohio). I agree that p53 should be considered a marker gene for the development of adenocarcinoma in Barrett's esophagus. This finding may be of importance in the laboratory study of the metaplasia, dysplasia, carcinoma sequence. To be clinically useful, however, this mutation should occur in all patients and should be detectable before the development of invasive carcinoma.

From your work and that of others, it appears that only half of the patients with Barrett's carcinoma have a mutation of this gene. There is also some disagreement as to when this mutation occurs.

Our experience suggests that this mutation occurs during the transition to HGD. In this study, HGD was observed in only three of 48 patients without Barrett's carcinoma, and one p53 mutation was detected. My first question concerns the sampling of this group, which consisted of two biopsies, one performed 1 to $2 \mathrm{~cm}$ above the cardia and one performed 1 to $2 \mathrm{~cm}$ below the squamocolumnar junction. Could you have underestimated the occurrence of HGD and the p53 mutation in this dysplastic epithelium by not using the standard Barrett's surveillance techniques of four quadrant biopsies every $2 \mathrm{~cm}$ along the Barrett's segment?

In the $\mathrm{BC}$ group, of the 23 patients with $\mathrm{p} 53$ mutations only five had this mutation detected in areas of HGD. Sixty-eight percent of these carcinomas were stage II or greater. My second question concerns a sampling of this group, which consisted of sampling only of three areas, the tumor, the peritumor Barrett's epithelium, and distant Barrett's epithelium. Could you have underestimated the occurrence of HGD and p53 mutations by this sampling protocol and by the invasion and destruction of the dysplastic forerunner of these late-stage carcinomas?

My third question concerns the clinical application of this information. What are your current recommendations about the search for p53 mutation in patients with Barrett's esophagus, and how would you manage the treatment of a patient with a p53 mutation and no evidence of invasive carcinoma?

Finally, Barrett's carcinoma is a disease of middle-aged and elderly white men. There were 15 women in your study, four with Barrett's carcinoma. Did the frequency and type of mutations in female patients differ from those seen in male patients?

Dr. Schneider. Concerning your first question, for the conventional studies we did four quarter biopsies as suggested by Reid. It is impossible to examine every single sample, and you may be right that we may therefore have underestimated the occurrence of p53 mutations. I suggest in the future the additional use of esophageal brushings, because we have done experiments that showed that one mutant cell in a million normal cells can be detected.

The problem of p53 mutations in peritumor Barrett's epithelium with HGD is complicated by the fact that if a tumor grows, peritumor Barrett's epithelium might be far away from the tumor center, especially with $\mathrm{T} 2$ or more advanced tumors. In two $\mathrm{T} 1$ categories, we have seen the identical mutations when there were mucosal-type carcinomas. You may also be right that we underestimated, but I think that there is just no way to determine this, especially for every tumor that is more than a mucosal cancer.

Dr. Rice. What is your recommendation for the sampling of Barrett's esophagus, and how would you manage the case of a patient with a p53 mutation and no invasive carcinoma?

Dr. Schneider. I commented on this. I think it is not 
possible to analyze four quarter biopsy samples molecularly. That is why I would consider using brushings.

How would I manage a patient with a p53 mutation? We would follow him or her up every 3 months. At my university hospital, we had one patient who underwent resection with HGD. This was a very young patient; he was 45 years old. He had repeated positive results on two occasional biopsies, and we decided to perform resection. This is a very unusual situation. We otherwise recommend repeated biopsies every 3 months. If one shows invasive cancer, we proceed with the resection. At the M. D. Anderson Cancer Center, however, which participated in our study, resection is recommended for Barrett's esophagus with severe dysplasia because of the high incidence of invasive cancers found in resected specimens.

Dr. Rice. Were there differences in the mutations between the male and female patients?

Dr. Schneider. We had so few female patients in the study that we cannot conclude anything.

Dr. Valerie W. Rusch (New York, N.Y.). At first glance, it may not appear that an analysis of p53 mutations in cancers related to Barrett's esophagus is clinically relevant. However, this type of study represents part of the future management of our patients.

During the last 20 years, we have meticulously defined the natural history of the common thoracic malignancies and have improved the surgical management of those malignancies. Despite this, there has been little improvement in overall survival for patients with lung or esophageal cancer. We need to understand the fundamental biologic changes associated with tumor initiation and progression to develop effective methods of early detection and novel treatment strategies. This carefully performed study is one step toward gaining that understanding.

The protein expression of the p53 gene can be altered either through gene mutation or by inactivation of a structurally normal p53 gene. The ubiquitous presence of p53 abnormalities in solid tumors suggests that it is part of an important pathway common to the development and growth of most cancers. Indeed, p53 is a multipotential gene. It is thought to modulate cell-cycle dynamics and to be a regulator of apoptosis, programmed cell death. Through its effects on apoptosis, it appears to influence responsiveness to both chemotherapy and radiation.

Previous work, both by you and by other investigators, examined p53 abnormalities by chromosomal analysis, flow cytometry, and immunohistochemistry, and suggested that altered p53 expression is frequent in cancers related to Barrett's esophagus. This study extends previous work in a precise and quantitative manner by directly examining gene mutations. You are to be commended for performing this biologic study across several institutions, something often easier said than done.

The findings of this study are similar to those recently reported with respect to preneoplastic bronchial epithelial lesions, namely that p53 abnormalities are seen in HGD, cancer in situ, and invasive cancers, but rarely in metaplasia or LGD. With regards to Barrett's cancers, an important clinical question for which we need a biologic answer is which molecular genetic abnormalities allow us to identify patients at risk for progression through the se- quence of metaplasia to dysplasia, and from varying grades of dysplasia on to invasive cancer.

I have a couple of questions. Have you started to do longitudinal follow-up of patients with dysplasia to confirm whether p53 abnormalities uniformly predict progression of dysplasia to cancer in situ or invasive cancer? In lung cancer, it has been shown that some tumors exhibit abnormal p53 expression by immunohistochemistry without having p53 gene mutations. This might explain the discrepancy between your results and previous immunohistochemical studies suggesting that p53 expression is abnormal even in LGD. Do you plan to do immunohistochemistry on your specimens to determine whether there is discordance between gene mutation and protein expression?

Dr. Schneider. To answer your first question, all of the patients are in a longitudinal study. Patients with NOD are evaluated with four quarter biopsies every 2 years, patients with LGD are evaluated once a year, and patients with HGD are evaluated, including p53 analysis, every 3 months. We have reevaluated approximately one third of those patients, and the results remain the same.

In reply to your second question concerning immunohistochemistry, one of the problems with immunohistochemistry is that neither lack of expression of p53 nor overexpression is absolutely associated with the process of malignant transformation. If there is a deletion mutation, which occurred in approximately $30 \%$ of our specimens, you will not be able to detect it by immunohistochemistry. You will have false-negative results, because the cell cannot make the protein, even though p53 is absent and cannot control the cell cycle. In the case of overexpression, you have approximately $10 \%$ false-positive results. The p53 analysis may be good if you have the immunohistochemistry in addition to a molecular analysis, but if you have the immunohistochemistry alone, you cannot really conclude a lot from those data. I would be very critical of using only immunohistochemistry. I have done immunohistochemistry for my set of patients, which constitute about $50 \%$ of the patients presented. We have concordance of the two methods in approximately $70 \%$ of cases, and in $30 \%$ we have mainly false-negative and very few false-positive results.

Dr. Victor F. Trastek (Rochester, Minn.). I think the key question is when to perform resection on these patients. We all appreciate that there is an opportunity to intervene in a carcinogenic process so that we can help the patient. It appears that we are all trying to figure out the exact time to proceed with resection. It is often as though the patient sits there with a bomb with a burning fuse; we just don't know how long the fuse is. We hope that techniques like this will help us to guess which patients have short fuses.

Therefore, I ask you, what are your indications for resection when you have a patient with HGD? I think you indicated that you would wait 3 months and resample, waiting for invasive carcinoma to be found. What evidence do you have that this is a successful technique in treating patients with HGD? As you know, a percentage of these patients will have occult invasive cancer. I think many of us feel that once the cancer is invasive the chance of lymph node disease goes up and the cat is out of the bag, 
or, stated differently, the bomb has exploded and it is probably too late.

Dr. Schneider. This is a very critical question. At the Technical University of Munich, we follow the policy of Reid's group. You remember that in the article in Gastroenterology approximately 1 or 2 years ago, Reid's group showed that they were quite good in following up patients with HGD with multiple biopsies and determining the time point when to resect. They recommended follow-up every 3 months from their experience. For my hospital, I can say that we are conservative in this respect. We resect when we have a biopsy specimen with invasive cancer, because there is a significant mortality rate associated with this procedure.

Dr. Arthur N. Thomas (San Francisco, Calif.). I am hesitant to bring this up, but in the last 25 years or so it seems to me that from about $5 \%$ of the patients that we treat with carcinoma of the esophagus to, in my practice now, nearly $50 \%$, have cancer related to Barrett's esophagus. I think this has come about by the unfortunate or unrelated events of treatment of reflux gastroesophagitis at a time when we are able to effectively prevent gastroesophagitis and reflux. Particularly more recently, with laparoscopic techniques, we are not seeing these patients because they are undergoing dilation, reendoscopy, and follow-up by the gastroenterologist for 10 or 15 years in some cases.

I recently had a case where exactly that was the situation. The patient had carcinoma associated with Barrett's esophagus that involved practically the entire esophagus, at $19 \mathrm{~cm}$ from the incisors. I just wonder about a third arm of this type of study, earlier treatment and prevention of Barrett's esophagus, and whether you have any patients that had the p53 changes that had undergone hiatus hernia repair where these changes regressed. What are your thoughts in this general area?

Dr. Schneider. We had only one patient with a mutation, and this patient underwent resection. As I said, this is a unique situation.

On the other hand, if I understand your question correctly, you imply that the reflux is causing the disease, or the reflux is causing the inflammation and the inflammation is causing the disease. There must be something more to it, however, because you know from the longitudinal studies, incidence studies of Barrett's cancer, that only a minor percentage of patients eventually acquire Barrett's cancer. I think it is still really unknown what the inducing mechanism is.

\section{Availability of JourNAL back issues}

As a service to our subscribers, copies of back issues of THE Journal of THORACiC AND CARdiovascular Surgery for the preceding 5 years are maintained and are available for purchase from the publisher, Mosby-Year Book, Inc., at a cost of $\$ 13.50$ per issue. The following quantity discounts are available: $25 \%$ off on quantities of 12 to 23 , and one third off on quantities of 24 or more. Please write to Mosby-Year Book, Inc., Subscription Services, 11830 Westline Industrial Drive, St. Louis MO 63146-3318, or call 800-453-4351 or 314-453-4351 for information on availability of particular issues. If unavailable from the publisher, photocopies of complete issues are available from University Microfilms International, 300 N. Zeeb Rd., Ann Arbor, MI 48106, $313-761-4700$. 